trol. We do contend, however, that the principles and practice of medicine cannot be taught by means of oral addresses. We care not what may be the lecturer's capabilities of speech,- what may be the extent of his information and his experience. It is not possible to convey correct impressions of disease to the mind through the ear, which should be imparted through the medium of another sense. The eye must be employed. The deviations from normal structure and function must be seen, before they can be adequately understood. Until, therefore, the rights of all medical men are placed on an equal footing with respect to the privilege of educating youths for the practice of medicine, we shall continue to exercise, fearlessly and unremittingly, whatever influence we may possess, in the hope of demolishing the ticket and certificate system of our incorporated hospitals and recognised schools.

(From a Correspondent.) - On Wednesday last an apothecary was elected by ballot (not by concours) at Westminster Hospital.

The numbers were as follows :-

Mr. Thurnam .......... 102

Mr. Alfred Hall ......... 68

Majority for Mr. Thurnam $\overline{34}$

Mr. Thurnam, a member of the society of Friends, was the protegé of the Artillery party, of whom Dr. Hallam is the great guv, and Dr. Wood the chief bombardier. As the mode of election had nothing to with the merit and competence of the party to fill the office, we have no one to congratulate on the result of the competition.

A GREAT meeting of the medical men residing in the Eastern part of England was appointed to be held at Bury St. Edmunds yesterday, Friday, the 25 th inst, for the purpose of forming an Eastern Provincial Medi. cal Association. The names of 150 medical gentlemen were attached to the requisition by which the meeting was called. The system of Poor-law contracts has been the ori ginating cause of the requisition.

\section{UNIVERSTTY OF LONDON AND COLLEGE OF SURGEONS.}

\section{To the Editor of THE LANCET.}

Sir,--Your comments on my letter of last week induce me again to address you. "You much doubt," you say, " if two things more unlike than the admission to an examination for a surgical diploma and the admission to compete for a chair in a medical school were ever before comparen." Things may be unlike, while the prineiples whence they result admit and require comparison. Your remarks necessarily lead ne to inquire on what principles the London University, and on what principles the College of Surgeons, were founded, and ought therefore to have been conducted. It will then be seen in which of the two bodies the conductors have most deviated, and in what direction, from those principles. The London University was established, and the sum of $110,000 l$. was subscribed, for the advancement and promotion of literature and science, and for the purpose of affording opportunities of attaining such branches of knowledge as were not previously taught in London; and it was declared that candidates for professorships should be treated with such strict regard to justice, that a difference in competency, even so slender as the hair that turns the balance, should determine the choice. Have these principles really been acted upon? The facts will speak for themselves. A large portion of the funds was expended upon a building, of which the dome alone cost about $20,000 l$. That building has since been mortgaged partly to erect an hospital, the officers to which were appointed without even the form of an election. Those branches of science, such as moral philosophy and jurisprudence, which required endowment and support, and which it was one of the first objects of the proprietors to cause to be cultivated, have been left unprotected. The professors, who should have been elected with such nice regard to justice, were chosen in a manner the least conducive to justice and impartiality. If these things have resulted from the management of the London University, its conductors must have deviated from the principles on which it was founded, and surely the deviation has been in the wrong direction. After this turn to the College of Surgeons.

That corporation was embodied by charter, and if its conduct has been in accordance with the principles of the charter, the Council must stand acquitted of the serious charges of misgovernment which the direc. tors of the London University have incurred. More than this: it cannot be denied that the changes made of late years by the College of Surgeons, have been marked by increasing justice and liberality; and, to revert to the case in question, the Council there acted upon principles more liberal than the charter itself seems to have prescribed; while the Council of the London University acted in a manner diametrically opposite to those principles of justice and liberality on which the institution was founded. The former might not be bound by the charter to admit me to examination and to recog. 
nise me as a lecturer, but I much question whether the latter, by the principles on which the University was founded, was not bound to allow a fair trial to those whom its professions had allured to become candidates for professorships, especially when many of those candidates were lecturers at private schools, whose legitimate interests have been largely sacrificed to the attractions which immense capital and high. sounding titles are wont to exercise.

These are the things that make men waver in their faith, and cause many to prefer old institutions which adapt themselves to the spirit of the age to new ones which profess to respect, but in practice sadly wrong it.

My object has not been to draw conclusions in favour of one body to the disadrantage of another body, but to advocate election by concours, and to show that in any attempts to improve medical government, it is right to look to facts and measures, rather than to professions and to men.

If the London University is, as you call it, a close body, and that which might have become a national institution has dwindled into a private establishment, the immense capital vested in it, the number, wealth, and power of its proprietors, have exercised an influence which seems to me to call for public inquiry. I remain your obedient servant

Hanover-street, September 23. T. KING.

[Want of space precludes us from offering any remarks in this week's LANCET on the contents of the above letter.-Ed.L.]

\section{ST. GEORGE'S HOSPITAL.}

\section{CASES OF HERNIA.}

Strangulated Inguteat Hernia Amos Cate, a carman, aged 28, was admitted with the following history and symptoms. He states that he has been subject to hernia for the last three years, which, however, he has always been able to reduce easily himself, so much so that he has never even worn a truss for it. At the time of his admission into the hospital, the hernia had been down for one hour, and vomiting had been present for half an hour. The pulse was 64 , and hard. The taxis was tried whilst he was on the bed, but without producing any effect on the tumour. He was then put into a warm-bath at $101^{\circ}$, which nearly reduced him to syncope; whilst in the bath he was bled to $\overline{3} \mathrm{xx}$, and syncope fully supervened, but no attempt made at reduction by the taxis succeded - the only perceptible difference being a slight relaxation in the tension of the stricture.

Finding these efforts unsuccessful, $\mathrm{Mr}$. WaLkER determined upon performing the operation, in the course of which the tunica vaginalis was opened and the testis exposed; this it was necessary to do, as the bowel was in all respects except time, similarly circumstanced as in congenital heraia. Omentum and intestine were found together in the sac; these were easily returned, and the wound was closed up and dressed in the usual manner. The operation was performed at four. p.m., and at nine p.m. he was quite easy; free from pain and slightly somnolent.

Eight a.m. On visiting him we found that he had passed a very comfortable night. Tongue white and furred; pulse 100, and natural ; there has been no alvine evacuation since the operation, but the bowels were slightly acted upon yesterday previous to his admission. An oily injection to be administered in the evening.

Oct. 1. 'The bowels opened once.

Sulphate of Magnesia jiss; Solution of Acetate of Ammonia ऊij; Camphor Mixture $\stackrel{5}{\mathrm{x}}$; every four hours.

3. The wound was dressed to-day, and found to be very nearly healed. The sutures were removed; the bowels are open every day. Repeat the draught.

7. The wound "progresses" well towards union; he has discontinued his medicine, and his general health is good.

14. He was discharged quite cured.

Strangulated Inguinal Hernia.A. James, aged 40, was almitted on the 20 th of July, at two a.m., with a tumour in the right inguinal region, of the size of an egg. He had all the usual symptoms of strangulatted intestine, sickness, hiccup, constipation of the bowels, \&c. He states that he has been subject to hernia for some years past, and until now he has been always able to retain the descended intestine easily himself. The hernia came down this time in consequence of his using some unusual exertion about eight hours previous to his admission.

He was placed in the warm-bath, and bled nearly to syncope, but withont any effect being produced upon the tumour. Sir BeNJAM IN BRo DIE (whose accident week it was) being absent, $M_{r}$. WALK a performed the operation at eight a.m. in the usual manner. A small portion of intestine and omentum was found in the sac-these were very easily reduced when the neck of the stricture had been divided.

No bad symptom followed the operation. During the period of his convalescence some sloughing of the sac took place, and a small abscess formed at the base of the scrotum, but these did not materially retard the progress of his recovery, and he was discharged perfectly cured on the 5th of September.

Strangulated Inguinal Hernia.Robert Wood, a Chelsea tailor, was admitted at ten p.m. He has been subject 